\title{
Evaluation of Urban Ecosystem Service Value under New Urbanization-A Case Study of Chengdu City
}

\author{
Yi Luo ${ }^{1}$, Shuang Liu ${ }^{2}$, Cheng Zhang ${ }^{3}$, Ruiying Ning ${ }^{4}$ and Jiajin Zhou ${ }^{5}$ \\ ${ }^{1}$ School of Business, Sichuan Agricultural University, Chengdu, Sichuan, China \\ ${ }^{2}$ School of Business, Sichuan Agricultural University, Chengdu, Sichuan, China \\ ${ }^{3}$ School of Business, Sichuan Agricultural University, Chengdu, Sichuan, China \\ ${ }^{4}$ School of Business, Sichuan Agricultural University, Chengdu, Sichuan, China \\ ${ }^{5}$ School of Business, Sichuan Agricultural University, Chengdu, Sichuan, China
}

\begin{abstract}
In order to evaluate the change of ecosystem service value in Chengdu, GIS technology was used to obtain the land use type data of Chengdu from 2009 to 2018. The equivalent factor method was used as the core evaluation method, and an ecosystem value evaluation model was established to explore the impact of various land use types on ecosystem service value. The results show that: (1) the trend of land use change is that both the area and the proportion of land use change in different degrees. The area of cultivated land, water area and unused land are greatly reduced, and the area of construction land expands rapidly, mainly through the occupation of cultivated land and unused land. (2) The intensity of land use in Chengdu is greater and continues to increase, and the contribution rate of construction land is larger, which indicates that the land use structure is developing towards the structural direction of mainly construction land. (3) Changes in ecosystem service value are not only related to land use structure, but also to the economic development, willingness to pay and ability of the whole society. (4) Ecosystem service value is negatively correlated with construction land and unused land; it is positively correlated with cultivated land, forest land and grassland. Generally speaking, Chengdu's land use change has not caused obvious damage to the ecosystem, but the impact of human lifestyle on the environment in the process of economic development cannot be ignored. The growth of construction land area should be appropriately controlled, ecological land should be protected, and the sustainable development of social-economic-ecological benefits should be realized.
\end{abstract}

\section{FOREWORD}

Ecosystem is a complex ecosystem composed of nature, people and society. Ecosystem services refer to all the benefits that human beings derive from ecosystems, including supply services, regulatory services, cultural services and support services ${ }^{[1]}$. In recent years, with the expansion of population and urbanization, people's demand for land development is increasing, and the original natural ecosystem of cities in the world is constantly being invaded, which leads to the degradation of many urban ecosystem services (Bojie $\mathrm{Fu}$ etc, 2014 ${ }^{[2]}$. The value of ecosystem services, as all human benefits from ecosystems, is closely linked to human well-being and regional sustainable development and is an important consideration in regional land use planning (Ziwen Liu etc,2019) ${ }^{[3]}$. If urban ecosystem services are not effectively planned and protected, cities may no longer be livable and their sustainable development may be threatened. "Ecological prosperity is civilization, ecological decline is civilization decline" is a concentrated embodiment of Xi Jinping's ecological civilization construction ideology and humanistic value, Chengdu will also consider ecological value in land planning, urban construction, adhere to the concept of green development, green water green mountain into Jinshan Silver Mountain. Taking Chengdu as an example, through the coupling study of land use change and ecosystem service value change, the influence of land use type change on ecosystem service value is discussed ${ }^{[4]}$.The specific research implications are as follows: (1) As far as the government is concerned, according to the land use situation, the analysis of the changes in the value of ecosystem services in Chengdu during the period of rapid development aims at providing decision support for the rational utilization of land resources and the protection of the urban ecological environment, which is of great theoretical significance and application value to the protection and reconstruction of the ecological environment and the sustainable development of the region. (2) As far as the regional economy is concerned, it provides a new thinking direction for the regional economy to realize the green transformation and green leapfrogging from the perspective of ecosystem 
service value assessment, and has important reference value for the formulation of the long-term development strategy of the regional economy. (3) As far as follow-up researchers are concerned, the study combines land-use change with ecosystem service value, which provides a new idea for ecosystem service value research, which is beneficial to enrich the impact of land-use change on ecosystem service value research, and provides a reference for follow-up related research.

\section{OVERVIEW OF RESEARCH AREA}

Chengdu is located on the western edge of Sichuan Basin, with a terrain sloping from northwest to southeast. The city is 192 kilometers long from east to west, 166 kilometers wide from north to south, and a total area of 12,390 square kilometers. Chengdu is rich in soil resources and has various types of soil. Land resources have the following characteristics: First, there are various types of land, which can be divided into 8 categories according to the current land use types, such as cultivated land, garden land and grassland. Second, the plain area ratio is significant, reaching 4,971.4 square kilometers, accounting for $40.1 \%$ of the city's total land area. Third, the land reclamation index is high, the land is fertile, the soil layer is deep, the climate is mild, irrigation is convenient, the proportion of usable area can reach $94.2 \%$, the city's average land reclamation index reaches $38.22 \%$, of which the plain area is as high as over $60 \%$. Chengdu's population grew steadily. By 2018 , Chengdu's resident population was 16.33 million, of which 11.9405 million were urban residents and the urbanization rate of the resident population was $73.12 \%$. In 2018 , the per capita disposable income of all residents in Chengdu was 36,142 yuan, up $8.8 \%$ year on year. Among them, the per capita disposable income of urban residents was 42128 yuan, up $8.2 \%$ year-on-year, 0.1 percentage point higher than that of the whole province. Per capita disposable income of rural residents was 22,135 yuan, up $9.0 \%$ year on year, the same as that of the whole province. In recent years, Chengdu has advocated the development of a green economy and vigorously promoted the construction of ecological civilization. As a new first-tier city, its total economic volume has reached a new level. In 2018, Chengdu's economic operation will be generally stable, with steady progress. The GDP of the region reached 1534.277 billion yuan, an increase of $8.0 \%$ over the same period of the previous year at comparable prices. The growth rate was 1.4 percentage points higher than that of the whole country, which was the same as that of the whole province. Among them, the added value of the primary industry reached 52.259 billion yuan, up $3.6 \%$. The added value of the secondary industry reached 651.619 billion yuan, up $7.0 \%$. The added value of the tertiary industry reached 830399 million yuan, up 9.0\%. The three industrial structures are 3.4: 42.5: 54.1.

\section{DATA AND METHODS}

\subsection{The data source}

The land use data from the chengdu city bureau of land and resources to carry out the second national land survey of statistical survey data of land use change, land use classification in accordance with national standards and the geological features of chengdu, chengdu city land use types can be divided into farmland, forest land, garden land, grassland, water area and wetland, construction land and unused land six grade class. The socio-economic data are from chengdu statistical yearbook and China statistical yearbook.

\subsection{The research methods}

\subsubsection{Analysis of land use change in chengdu city}

(1) Analysis of land use intensity and structure change. The change of land use is mainly reflected by the change of land use intensity and use mode. The comprehensive index of annual land use intensity and the intensity contribution rate of a single land use type during the 10 years from 2009 to 2018 were studied to analyze the change mode of land use in chengdu during the 10 years.

(2) Land use intensity analysis

Comprehensive land use intensity index, reflecting the overall change of all land types:

$$
I=\sum\left(\mathrm{Li}_{\mathrm{i}} \times P_{i}\right) \times 100 \%
$$

$I$ represents the comprehensive index of land use intensity, $L_{i}$ represents the grade of land use intensity of class $i$ land use types, and $P_{i}$ represents the proportion of class $i$ land use types in the total land area.

The contribution rate of the utilization intensity of a single land type reflects the influence of a single land use type on the change of the comprehensive index of land use intensity.

$$
\mathrm{R}_{i}=\frac{I_{i b}-I_{i a}}{I_{i a}}=\frac{L_{i} \times\left(P_{i b}-P_{i a}\right)}{L_{i} \times P_{i a}}
$$

$R_{i}$ is the contribution rate of the comprehensive index of land use intensity of class $i$ in chengdu from year $a$ to year $b ; I_{i b}$ and $I_{i a}$ are the land use intensity indexes of type i land use types in year $b$ and year $a$ in chengdu. $P_{i b}$ and $P_{i a}$ are the ratio of class $i$ land use types to the total land area in year $b$ and year $a$ in chengdu. $L_{i}$ represents the grade of land use intensity of class $i$ land use types $[5][6]$. 
Table 1. Evaluation table of chengdu land use intensity grade.

\begin{tabular}{|l|c|c|c|c|c|}
\hline & Unutilized stage & Light utilization grade & Low utilization level & Strong utilization level & Strong utilization level \\
\hline Land use type & Unutilized land & waters & Woodland, grassland & $\begin{array}{c}\text { Cultivated land and } \\
\text { other agricultural land }\end{array}$ & Construction land \\
\hline Intensity rating & 1 & 2 & 3 & 4 & 5 \\
\hline
\end{tabular}

Table 2. Comprehensive index of land use intensity in chengdu.

\begin{tabular}{|c|c|}
\hline Year & Chengdu Land Use Intensity Composite Index (\%) \\
\hline 2009 & 445.18 \\
\hline 2010 & 444.24 \\
\hline 2011 & 444.02 \\
\hline 2012 & 441.08 \\
\hline 2013 & 440.12 \\
\hline 2014 & 448.2 \\
\hline 2015 & 450.2 \\
\hline 2016 & 451.02 \\
\hline 2017 & 452.29 \\
\hline 2018 & 453.87 \\
\hline
\end{tabular}

Table 3. Chengdu land use area statistical unit: square kilometers.

\begin{tabular}{|c|c|c|c|c|c|c|c|c|c|c|}
\hline & 2009 & 2010 & 2011 & 2012 & 2013 & 2014 & 2015 & 2016 & 2017 & 2018 \\
\hline arable land & 4285.53 & 4284.46 & 4109.54 & 4038.90 & 3894.18 & 3723.29 & 3598.27 & 3423.21 & 3376.29 & 3179.24 \\
\hline woodland & 3533.51 & 3533.58 & 3549.15 & 3564.71 & 3580.28 & 3595.85 & 3611.41 & 3606.84 & 3602.26 & 4544.94 \\
\hline Grassland & 659.43 & 659.31 & 649.57 & 639.83 & 630.09 & 620.35 & 610.61 & 610.42 & 610.24 & 674.09 \\
\hline waters & 222.75 & 222.75 & 224.99 & 227.24 & 229.48 & 231.72 & 233.96 & 233.77 & 233.58 & 164.50 \\
\hline $\begin{array}{c}\text { construction } \\
\text { land }\end{array}$ & 1774.17 & 1774.16 & 1853.45 & 1932.75 & 2012.04 & 2091.33 & 2170.62 & 2285.11 & 2399.57 & 2050.42 \\
\hline $\begin{array}{c}\text { Unutilized } \\
\text { land }\end{array}$ & 40.28 & 36.27 & 34.29 & 31.28 & 26.09 & 24.64 & 23.28 & 22.29 & 22.18 & 21.99 \\
\hline
\end{tabular}

As can be seen from the table, the comprehensive index of land use intensity of chengdu fluctuates between 445 and 453, indicating that the city is in the transition from low to strong use, indicating that chengdu is in the development period of land use, and the potential of land development and use in the later period is still large. Land use intensity index of chengdu changes appear to fall after a rise in volatility, but since 2013 , the overall rise, and since 2016, rising amplitude increase, accelerating urbanization and industrialization process of chengdu, the land use intensity level to develop in the direction of higher level and later as the industrialization and urbanization speed, the intensity of land development and utilization of chengdu will continue to increase.

Table 4. Contribution Rate of Various Land Use Types to Comprehensive Land Use Index in Chengdu.

\begin{tabular}{|c|c|c|c|c|c|c|}
\hline & arable land & woodland & Grassland & waters & Construction land & Unutilized land \\
\hline $\begin{array}{c}\text { Contribution Rate of } \\
\text { Land Use Intensity (\%) }\end{array}$ & -0.2570 & 0.2861 & 0.0226 & -0.2611 & 0.1557 & -0.4849 \\
\hline
\end{tabular}

Can be seen from the table, in the 10 years from 2009 to 2018 of chengdu, arable land, water area, the contribution rate of unused land is negative, the value of construction land and forest land, meadow and is positive, but the general land use intensity index is rising, forest land and its contribution is the largest, the second is to use construction land, that land use structure is to the main direction of ecological priority, followed by the shift in the direction of construction land for the time.
Note that the contribution rate of unused land is large and negative, indicating that a large number of unused land is reclaimed for forestland and construction land, which also confirms that the land use structure of chengdu is developing towards green development, ecological priority and construction land. 


\subsubsection{Systematic evaluation of ecosystem service value in chengdu}

(1) The construction of service value evaluation model of ecosystem. Based on existing studies, this paper defines the economic value equivalent of natural grain output of 1 hectare of farmland with national average yield in a year as 1 , and the corresponding ecosystem services are farmland food production services ${ }^{[7]}$. Furthermore, according to the contribution of other ecosystem services to farmland food production services, their respective equivalent factors were determined, and the scale of ecological service value per unit area of China's terrestrial ecosystem was drawn. On the basis of the above work, adjust the corresponding impact factors according to the actual situation of chengdu, and construct the value evaluation model of ecosystem services:

$$
E S V=\sum\left(A_{k} \times V C_{k} \times S_{k} \times S_{n}\right)
$$

$E S V$ is the value of ecosystem services (yuan); $A_{k}$ is the area of class $k$ land use type $(\mathrm{hm} 2) ; V C_{k}$ is the value coefficient, representing the service value per unit area of the land use type $k$ (yuan $/ \mathrm{hm} 2$ ); $S_{k}$ is the adjustment coefficient of biomass factor, while $S_{n}$ is the adjustment coefficient of social and economic factors calculated based on residents' willingness to pay and ability to pay $[8]$.

Value of food production service in farmland ecosystem per unit area. With reference to existing studies, the value of food production services in the farmland ecosystem was taken as equivalent 1 , and then the value of other ecosystems was calculated based on the equivalent factor table ${ }^{[9]}$ :

$$
\mathrm{E}_{n}=\left(P \times Q_{n} / M_{n}\right) \times \frac{1}{7}
$$

$E_{n}$ is the economic value of food provided per unit area of farmland in chengdu; $P$ is the average price of grain crops in year $n$ in chengdu, and $Q_{n}$ is the total output of all grain crops in chengdu in year $n . M_{n}$ is the cultivated land area of chengdu in the NTH year. To eliminate the factors of price changes in each year, $P$ is the average price of grain crops in 2017.

Biomass factor adjustment. Assuming a linear relationship between biomass and ecosystem service value, the biomass factor is adjusted by comparing the net primary productivity of vegetation in different regions.

$$
S_{k}=\frac{N P P_{s}}{N P P_{g}}
$$

$N P P_{s}$ is the net primary productivity of vegetation in chengdu. $N P P_{g}$ is the net primary productivity of national vegetation; $S_{k}$ is the adjusting coefficient of biomass factor.

$$
\begin{gathered}
\mathrm{NPP}=3000\left[1-e^{-0.000969 \varangle V-20)}\right] \\
\mathrm{V}=\frac{1.05 \operatorname{Pr} e}{\sqrt{1+(1+1.05 \operatorname{Pr} e / L)^{2}}} \\
\mathrm{~L}=3000+25 T m p+0.05 T m p^{3}
\end{gathered}
$$

$N P P$ is the net primary productivity of vegetation in the study area. $V$ is the actual annual evapotranspiration; Pre is annual precipitation; $L$ is the average annual evapotranspiration; Tmp is the average annual

\begin{tabular}{|c|c|c|c|c|c|c|c|}
\hline Primary type & Secondary type & arable land & woodland & Grassland & waters & Construction land & Unutilized land \\
\hline \multirow{2}{*}{$\begin{array}{l}\text { Supply } \\
\text { service }\end{array}$} & $\begin{array}{c}\text { Food } \\
\text { production }\end{array}$ & 1 & 0.19 & 0.24 & 0.30 & 0.006 & 0.122 \\
\hline & $\begin{array}{l}\text { Raw material } \\
\text { production }\end{array}$ & 0.22 & 1.69 & 0.20 & 0.20 & 0 & 0.10 \\
\hline \multirow{4}{*}{$\begin{array}{l}\text { Adjustment } \\
\text { service }\end{array}$} & gas regulation & 0.41 & 2.45 & 0.85 & 0.29 & 0 & 0.43 \\
\hline & $\begin{array}{c}\text { Climate } \\
\text { regulation }\end{array}$ & 0.55 & 2.31 & 0.89 & 1.17 & 0 & 0.44 \\
\hline & $\begin{array}{l}\text { Hydrological } \\
\text { regulation }\end{array}$ & 0.44 & 2.32 & 0.86 & 10.66 & -4.27 & 0.43 \\
\hline & waste disposal & 0.79 & 0.98 & 0.75 & 8.44 & -1.40 & 0.375 \\
\hline \multirow{2}{*}{$\begin{array}{l}\text { Support } \\
\text { services }\end{array}$} & Maintain soil & 0.84 & 2.28 & 1.27 & 0.23 & 0.011 & 0.64 \\
\hline & $\begin{array}{l}\text { Maintaining } \\
\text { biodiversity }\end{array}$ & 0.58 & 2.56 & 1.06 & 1.95 & 0.19 & 0.53 \\
\hline $\begin{array}{l}\text { Cultural } \\
\text { services }\end{array}$ & $\begin{array}{c}\text { Provide } \\
\text { aesthetic } \\
\text { landscape }\end{array}$ & 0.10 & 1.18 & 0.49 & 2.52 & 0.006 & 0.25 \\
\hline \multicolumn{2}{|c|}{ Total } & 4.93 & 15.96 & 6.61 & 25.76 & -5.46 & 3.317 \\
\hline
\end{tabular}
temperature. $\quad \mathrm{NPPg}=376 \mathrm{~g} / \mathrm{m} 2, \quad \mathrm{NPPs}=663 \mathrm{~g} / \mathrm{m} 2$ in chengdu, and $\mathrm{S}_{\mathrm{K}}=1.76$ in chengdu. According to the adjusted coefficient of biomass factor, the scale is as follows:

Table 5. Chengdu Ecological Service Value Scale Adjusted by Biomass Factors. 
(3) Adjustment of socio-economic factors. Considering the influence of social and economic conditions on willingness to pay and ability to pay, the calculation model of adjustment coefficient of social and economic factors in chengdu is as follows:

$$
S_{n}=P_{n} \times R_{n}
$$

$S_{n}$ is the adjustment coefficient of social and economic factors in the NTH year of chengdu, while $P_{n}$ is the coefficient of willingness to pay of chengdu. $R_{n}$ is chengdu's capacity to pay coefficient.

The calculation formula of willingness to pay coefficient is as follows:

$$
\begin{gathered}
P_{n}=\frac{W_{q n}}{W_{g n}} \\
\mathrm{~W}=\frac{2}{\left(1+a e^{-b m}\right)} \\
m=\frac{1}{E L n}-2.5 \\
E L_{n}=E L c_{n} \times \operatorname{Pec}_{n} \times E L r_{n} \times \operatorname{Per}_{n} \mathrm{n}
\end{gathered}
$$

$P_{n}$ is the willingness to pay coefficient of chengdu in $\mathrm{n}$ years; $W_{q n}$ is the willingness to pay parameter of chengdu in year $\mathrm{n} ; W_{g n}$ is the national average willingness to pay in $\mathrm{n}$ years; Parameter $m$ is the coefficient of social development stage; $b$ in chengdu is 1 ; $E L_{n}$ is the total engel coefficient of the research area in the NTH year; $E L c_{n}$ represents the rural engel coefficient of the study area; $P e c_{n}$ is the proportion of rural population in the total population; $E L r_{n}$ represents the engel coefficient of the cities in the study area; $P e r_{n}$ refers to the proportion of urban population in the total population.

Table 6. Calculation Results of Chengdu Willingness to Pay Coefficient.

\begin{tabular}{|c|c|c|c|}
\hline & $\begin{array}{c}\text { Chengdu } \\
\text { Willingness } \\
\text { to Pay } \\
\text { Parameters }\end{array}$ & $\begin{array}{c}\text { National } \\
\text { Willingness } \\
\text { to Pay } \\
\text { Parameter }\end{array}$ & $\begin{array}{c}\text { Chengdu } \\
\text { Willingness } \\
\text { to Pay } \\
\text { Coefficient }\end{array}$ \\
\hline 2009 & 0.969 & 1.036 & 0.935 \\
\hline 2010 & 1.005 & 1.032 & 0.974 \\
\hline 2011 & 1.007 & 1.025 & 0.982 \\
\hline 2012 & 0.994 & 0.914 & 1.087 \\
\hline 2013 & 1.025 & 0.938 & 1.092 \\
\hline 2014 & 1.039 & 0.893 & 1.116 \\
\hline 2015 & 1.042 & 0.876 & 1.189 \\
\hline 2016 & 1.057 & 0.760 & 1.390 \\
\hline 2017 & 1.068 & 0.592 & 1.804 \\
\hline 2018 & 1.063 & 0.542 & 1.961 \\
\hline
\end{tabular}

The calculation formula of capacity to pay coefficient is as follows:

$$
R_{n}=\frac{g d p_{n} / c p O_{n}}{G D P_{n} / N P O_{n}}
$$

$R_{n}$ represents the capacity to pay coefficient of chengdu in $\mathrm{n}$ years; cpo $_{n}$ represents the total population of chengdu in $\mathrm{n}$ years; gdpn represents the GDP of chengdu in $\mathrm{n}$ year; $G D P_{n}$ represents the total gross domestic product of the country in $\mathrm{n}$ years. $\mathrm{NPo}_{n}$ is the total population of the country in the NTH year.

Table 7. Calculation Results of Chengdu's Capacity to Pay Coefficient.

\begin{tabular}{|c|c|c|c|}
\hline & $\begin{array}{c}\text { Per capita GDP } \\
\text { of Chengdu } \\
\text { (yuan/person) }\end{array}$ & $\begin{array}{c}\text { National GDP } \\
\text { Per Capita } \\
\text { (Yuan/Person) }\end{array}$ & $\begin{array}{c}\text { Coefficient } \\
\text { of capacity } \\
\text { to pay }\end{array}$ \\
\hline 2009 & 20110.93 & 26179.54 & 0.768 \\
\hline 2010 & 39208.82 & 30807.93 & 1.272 \\
\hline 2011 & 39518.42 & 36301.56 & 1.088 \\
\hline 2012 & 57609.83 & 39874.28 & 1.444 \\
\hline 2013 & 63476.59 & 43684.39 & 1.453 \\
\hline 2014 & 70611.37 & 47005.40 & 1.502 \\
\hline 2015 & 74273.52 & 50027.93 & 1.484 \\
\hline 2016 & 77470.47 & 53679.52 & 1.443 \\
\hline 2017 & 87260.21 & 59200.61 & 1.473 \\
\hline 2018 & 96033.67 & 64643.50 & 1.481 \\
\hline
\end{tabular}

Table 8. Calculation Results of Adjustment Coefficient of Chengdu's Social and Economic Factors.

\begin{tabular}{|c|c|c|c|}
\hline & $\begin{array}{c}\text { Willingness } \\
\text { to Pay } \\
\text { Coefficient }\end{array}$ & $\begin{array}{c}\text { Coefficient } \\
\text { of capacity } \\
\text { to pay }\end{array}$ & $\begin{array}{c}\text { Adjustment } \\
\text { coefficient of } \\
\text { social and } \\
\text { economic factors }\end{array}$ \\
\hline 2009 & 0.935 & 0.768 & 0.718 \\
\hline 2010 & 0.974 & 1.272 & 1.238 \\
\hline 2011 & 0.982 & 1.088 & 0.989 \\
\hline 2012 & 1.087 & 1.444 & 1.569 \\
\hline 2013 & 1.092 & 1.453 & 1.586 \\
\hline 2014 & 1.116 & 1.502 & 1.676 \\
\hline 2015 & 1.189 & 1.484 & 1.764 \\
\hline 2016 & 1.390 & 1.443 & 2.005 \\
\hline 2017 & 1.804 & 1.473 & 2.657 \\
\hline 2018 & 1.961 & 1.481 & 2.902 \\
\hline
\end{tabular}

Valuation of ecosystem services. According to the existing Chinese land ecosystem unit area ecosystem service value when scale, adjust the corresponding biomass factors and social economic factors, formulated in accordance with the actual situation of chengdu chengdu ecosystem ecological service value per unit area yield, then respectively the area multiplied by the value of the ecosystem when scale to calculate the unit value, finally it is concluded that the ecosystem service value.

$$
E S V=\sum\left(A_{k} \times V C_{k} \times S_{k} \times S_{n}\right)
$$


Table 9. Ecological Service Value per Unit Area of Chengdu Ecosystem..

\begin{tabular}{|c|c|c|c|c|c|c|c|}
\hline Primary type & Secondary type & arable land & woodland & Grassland & waters & Construction land & Unutilized land \\
\hline \multirow{2}{*}{$\begin{array}{l}\text { Supply } \\
\text { service }\end{array}$} & Food production & 1 & 0.33 & 0.43 & 0.53 & 0.01 & 0.215 \\
\hline & $\begin{array}{l}\text { Raw material } \\
\text { production }\end{array}$ & 0.39 & 2.98 & 0.36 & 0.35 & 0 & 0.18 \\
\hline \multirow{4}{*}{$\begin{array}{l}\text { Adjustment } \\
\text { service }\end{array}$} & gas regulation & 0.72 & 4.32 & 1.5 & 0.51 & 0 & 0.75 \\
\hline & $\begin{array}{c}\text { Climate } \\
\text { regulation }\end{array}$ & 0.97 & 4.07 & 1.56 & 2.06 & 0 & 0.78 \\
\hline & $\begin{array}{l}\text { Hydrological } \\
\text { regulation }\end{array}$ & 0.77 & 4.09 & 1.52 & 18.77 & -7.51 & 0.76 \\
\hline & waste disposal & 1.39 & 1.72 & 1.32 & 14.85 & -2.46 & 0.66 \\
\hline \multirow{2}{*}{$\begin{array}{l}\text { Support } \\
\text { services }\end{array}$} & Maintain soil & 1.47 & 4.02 & 2.24 & 0.41 & 0.02 & 1.12 \\
\hline & $\begin{array}{l}\text { Maintaining } \\
\text { biodiversity }\end{array}$ & 1.02 & 4.51 & 1.87 & 3.43 & 0.34 & 0.935 \\
\hline $\begin{array}{l}\text { Cultural } \\
\text { services }\end{array}$ & $\begin{array}{c}\text { Provide aesthetic } \\
\text { landscape }\end{array}$ & 0.17 & 2.08 & 0.87 & 4.44 & 0.01 & 0.435 \\
\hline \multicolumn{2}{|c|}{ Total } & 7.9 & 28.12 & 11.67 & 45.35 & -9.59 & 5.835 \\
\hline
\end{tabular}

Table 10. Total Value of Ecological Services of Various Land Types in Chengdu: RMB 10,000 Yuan.

\begin{tabular}{|c|c|c|c|c|c|c|c|}
\hline Year & arable land & woodland & Grassland & waters & Construction land & Unutilized land & total \\
\hline 2009 & 9233.2 & 27036.8 & 2098.8 & 2754.9 & -4640.2 & 64.1 & 36547.6 \\
\hline 2010 & 15962.2 & 46859.9 & 3628.6 & 4763.9 & -8023.8 & 99.8 & 63290.6 \\
\hline 2011 & 12393.7 & 44115.4 & 2893.9 & 3895.1 & -6785.5 & 76.4 & 56589.0 \\
\hline 2012 & 19429.8 & 60733.4 & 4546.9 & 6275.1 & -11286.8 & 111.1 & 79809.5 \\
\hline 2013 & 18508.0 & 60568.9 & 4423.8 & 6260.9 & -11608.4 & 91.6 & 78244.8 \\
\hline 2014 & 18952.8 & 65207.6 & 4664.7 & 6771.1 & -12922.9 & 92.6 & 82765.9 \\
\hline 2015 & 19586.5 & 69972.5 & 4909.9 & 7310.6 & -14342.9 & 93.6 & 87530.2 \\
\hline 2016 & 19136.5 & 73561.1 & 5040.8 & 7501.8 & -15506.9 & 92.0 & 89825.3 \\
\hline 2017 & 25465.4 & 96710.5 & 6799.2 & 10113.4 & -21970.5 & 123.6 & 116994.4 \\
\hline 2018 & 27217.9 & 120000 & 8525.0 & 8084.4 & -21309.1 & 139.0 & 185275.4 \\
\hline
\end{tabular}

\section{CONCLUSION AND DISCUSSION}

\subsection{Conclusion}

Based on the analysis of the dynamic change of land use in Chengdu from 2009 to 2018, the estimation of ecosystem service value and the research results of the impact of land use change on ecosystem service value, we know that:

(1)From 2009 to 2018, the area of cultivated land, water area and unused land in the research area decreased significantly, and the area of construction land expanded rapidly, mainly through the occupation of cultivated land and unused land. A small part of water area was converted into woodland and grassland. The trend of land use change is that both the area and the proportion of land use change to different degrees. The transfer among various land use types has to some extent resulted in the reduction of land structure order degree, the deterioration of equilibrium degree and the instability of land use system.

(2)Chengdu's land use intensity is relatively high and continues to increase: with the acceleration of urbanization and industrialization in Chengdu, the intensity level of land use is developing to a higher level and will continue to increase. the contribution rate of construction land is relatively large, which indicates that Chengdu's land use structure is developing towards a structure dominated by construction land.

(3)The change trend of each land type and the total value of ecosystem services in the region is basically the same, especially in the water area, cultivated land and unused land, and there is a big difference in the change speed of other lands. This shows that the change of ecosystem service value is not only related to the structure of land use, but also to the economic development, willingness to pay and ability of the whole society.

(4)The ecosystem service value of land use in Chengdu increased from 2009 to 2018 , but the increase rate was lower and lower. Cultivated land and forest land contributed the most to the total increase of ecosystem service value, while the value of ecosystem service value of construction land was negative. There is a negative correlation between construction land and ecosystem service value. The growth of construction land should be properly controlled to ensure that the grassland and farmland are not reduced. It is extremely important to protect ecological land and take the road of ecological-economic sustainable development to promote green development. 


\section{2 discussion}

The evaluation of ecosystem service value is affected by many factors. If different methods are adopted, the absolute value of ecosystem service value will vary greatly, but it will not affect its temporal and spatial variation law. Based on the research of Xie Gaodi and others, and based on the change of land use pattern in Chengdu from 2009 to 2018, this paper uses the equivalent factor method to analyze and evaluate the ecosystem service value of Chengdu in the past ten years. Although this method can reveal the evolution of temporal and spatial distribution pattern of ecosystem service value in Chengdu in the past ten years to a certain extent, there are still some deficiencies, which need further discussion and research.

(1) The internal structure of the ecosystem is relatively complex, and the service value of the ecosystem is affected by various factors. In this paper, in the process of evaluating the ecosystem service value of Chengdu, the biomass factor and social economic factor were adjusted according to the actual situation of Chengdu. The results obtained have certain reference significance. However, this study only analyzes the temporal and spatial evolution of ecological service value in the study area from the perspective of land use change, and lacks comprehensive consideration of other influencing factors. (2) This paper evaluates the ecosystem service value of various land use types in Chengdu by referring to relevant documents. By comparing the ecosystem service value of various land use types in ten years, it is concluded that the increase of construction land is an important reason that affects the slow growth of ecosystem service value in the study area. However, due to the complex ecological service function of construction land and limited data acquisition, it is difficult to define the scope and extent of its impact. This paper has not made an in-depth analysis of this problem, and there are still some shortcomings, which need to be further discussed in the future.

\section{References}

1. Zhao Shidong, Zhang Yongmin. Ecosystem and Human Well-being-Achievements, Contributions and Prospects of Millennium Ecosystem Assessment [J]. Progress in Earth Science,2006(09):895-902.

2. Fu Bojie, Tian Hanqin, Tao Fulu, Zhao Wenwu, Wang Shuai. Impact of Global Change on Ecosystem Services [J]. Basic Science of China, 2017, 19(06):14-18.

3. Liu Ziwen, Yin Dan, Huang Qingxu, He Chunyang, Xue Fei. Progress in Research and Application of Ecosystem Services in Land Use Planning-Based on Bibliometrics and Text Analysis [J].Advances in Geographical Science,2019,38(02):236-247.

4. Ai Zhihua. Study on the Impact of Land Use Change on Ecosystem Service Value in Qianjiang City [D]. Huazhong Normal University,2013.

5. Liu Xiaofeng, Ma Jinsong, Pan Ying. Dynamic Monitoring of Land Use Intensity Change in Dongchangfu District of Liaocheng City [J]. Hydroelectric Energy Science,2009,27(02):149-151.

6. Wan Li, Chen Youqi, Tan Jing, Guo Bin, Yang Aqiang. Impact of Land Use Change on Regional Ecosystem Service Value-A Case Study of Beijing [J]. Regional Research and Development,2009,28(04):94-99+109.

7. Zhang Zhou, Wu Cifang, Tan Rong. Application of Ecosystem Service Value in Land Use Change Research: Bottlenecks and Prospects [J]. Journal of Applied Ecology,2013,24(02):556-562.

8. Ai Zhihua. Study on the Impact of Land Use Change on Ecosystem Service Value in Qianjiang City [D]. Huazhong Normal University,2013.

9. Xie Gaodi, Xiao Yu, et al. Study on the Ecological Service Value of Grain Production in China [J]. Journal of China Ecological Agriculture. 2005, 13(3):10-13. 